\title{
CORRECTION
}

\section{Correction: Screening and control of methicillin-resistant Staphylococcus aureus in 186 intensive care units: different situations and individual solutions}

Anke Kohlenberg ${ }^{* 1}$, Frank Schwab ${ }^{2,3}$, Michael Behnke ${ }^{2,3}$ and Petra Gastmeier2,3

\section{Correction}

Following publication of our article [1], Dr Christine Geffers has been removed as co-author.

\section{Competing interests}

The authors have no competing interests.

\section{Author details}

IInstitute for Medical Microbiology, Immunology and Hygiene, University of Cologne, Goldenfelsstrasse 19-21, 50935 Cologne, Germany. Institute of Hygiene and Environmental Medicine, Charité University Medicine Berlin, Hindenburgdamm 27, 12203 Berlin, Germany. ${ }^{3}$ National Reference Centre for Surveillance of Nosocomial Infections, Hindenburgdamm 27, 12203 Berlin, Germany.
Published: 8 February 2012

\section{Reference}

1. Kohlenberg A, Schwab F, Behnke M, Geffers C, Gastmeier P: Screening and control of methicillin-resistant Staphylococcus aureus in 186 intensive care units: different situations and individual solutions. Critical Care 2011, 15:R285

\section{doi:10.1186/cc11179}

Cite this article as: Kohlenberg A, et al.: Correction: Screening and control of methicillin-resistant Staphylococcus aureus in 186 intensive care units: different situations and individual solutions. Critical Care 2012, 16:402.

${ }^{*}$ Correspondence: akohlenberg@gmx.de

'Institute for Medical Microbiology, Immunology and Hygiene, University of

Cologne, Goldenfelsstrasse 19-21, 50935 Cologne, Germany

Full list of author information is available at the end of the article 